\title{
Association of transferrin polymorphism with different economic traits of Garole sheep
}

\author{
D. K. Yadav, S. Taraphder*, K. C. Dhara , S. Batabyal, I. Samanta and M. Mitra \\ West Bengal University of Animal and Fishery Sciences, 68 K.B. Sarani, Kolkata-37, West Bengal, India.
}

Accepted 30 December, 2011

\begin{abstract}
The present study was carried out on 52 apparently healthy adult ewes of Garole sheep reared at Sheep and Goat Breeding Farm of West Bengal University of Animal and Fishery Sciences, during April to September 2009 to investigate the association of transferrin polymorphism with different economic traits. The nine transferrin genotypes were identified by Vertical Sodium Dodecyl sulfate Polyacrylamide gel electrophoresis technique. Four (Transferrin AA, BB, CC and DD ) of these were homozygous and the remaining five (Transferrin $A D, B C, B D, C D$ and $D E$ ) heterozygous. The performance of different economic traits in respect of different genotypes of transferrin was analysed. The analysis of data revealed that Garole sheep at this farm produced $2.05 \pm 0.23$ lambs per lambing. Sheep with TfAD genotype showed the best performance with respect to lamb production $(2.71 \pm 0.28$

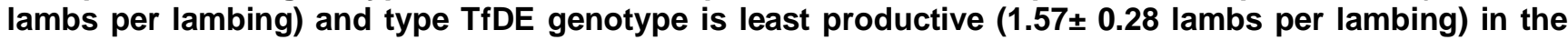
analyzed ewe flock. Average number of lambs born in heterozygous and homozygous ewes was $2.16 \pm 0.18$ and $1.99 \pm 0.25$ in overall lambing, respectively. It was found that the overall mean of age at first lambing was $479.88 \pm 4.27$ days. Maximum value of age at first lambing (522.25 \pm 22.56 days) corresponds to sheep having TfAA genotype. Lowest age at first lambing $(447.00 \pm 13.00$ days) was shown by animal having TfAD genotype. On an average, the heterozygous ewes at the transferrin locus had shorter age at first lambing $(471.323 \pm 5.26$ days) with respect to homozygous ewes at transferrin locus (492.52 \pm 6.39 days). Overall lambing interval was found to be $256.44 \pm 9.51$ days in the herd. The results of lambing interval showed that ewes having TfBB genotype had $237.86 \pm 7.37$ days while ewes having TfCC genotype had $265.75 \pm 9.75$ days. Analysis of variance showed that transferrin polymorphism had significant effect on number of lambs born in second $\left({ }^{\star *} P<0.01\right)$ and overall lambing $\left({ }^{\star} \mathrm{P}<0.05\right)$. Analysis of variance showed that between genotype analysis had significant $\left({ }^{\star} \mathrm{P}<0.05\right)$ effect on average number of lamb produced in overall lambing. Between genotype, analysis of variance that transferrin genotypes had significant $\left({ }^{\star \star} P<0.01\right)$ effect on age at first lambing. Analysis of variance showed that transferrin genotypes had significant effect $\left({ }^{*} \mathrm{P}<0.05\right)$ in first lambing interval. The heterozygous ewes tended to have a better production performance than the homozygous ewes. This genetic information of transferrin gene could be useful in marker assisted selection to improve production performance.
\end{abstract}

Key words: Sheep, Garole, transferrin, polymorphism, prolificacy, age at first lambing and lambing interval.

\section{INTRODUCTION}

Small ruminants have a unique role in Indian meat sector having prime importance in production and consumption by large ample. Most important Eastern region sheep

*Corresponding author. E-mail: subhash.taraphder
@gmail.com. breed found in West Bengal is Garole which is dwarf, highly prolific, has short lambing interval and of coarse wool type. The ewes should be prolific and must have good mothering ability. So selection program should be taken to increase their productivity. Lower days of age at first lambing, more number of lambs per lambing and less number of days for lambing interval are very much important for economic rearing of sheep. Transferrin, one 
Table 1. Mean \pm SE of Number of lambs produced in first, second, third and overall lambing in investigated flock of Garole sheep in respect of genotypes.

\begin{tabular}{lcccc}
\hline \multirow{3}{*}{ Genotypes } & \multicolumn{4}{c}{ Traits } \\
\cline { 2 - 4 } & \multicolumn{4}{c}{ Number of lamb produced in } \\
\cline { 2 - 4 } & $1.25 \pm 0.25(4)$ & $2.50 \pm 0.25(4)$ & $2.50 \pm 0.25(4)$ & $2.08 \pm 0.25(12)$ \\
\hline Tf AA & $2.33 \pm 0.33(3)$ & $3.00 \pm 0.49(2)$ & $3.00 \pm 0.40(2)$ & $2.71 \pm 0.28(7)$ \\
Tf AD & $1.75 \pm 0.48(4)$ & $1.75 \pm 0.25(4)$ & $2.33 \pm 0.33(3)$ & $1.91 \pm 0.25(11)$ \\
Tf BB & $2.50 \pm 0.52(2)$ & $3.00 \pm 0.49(2)$ & $1.50 \pm 0.49(2)$ & $2.33 \pm 0.35(6)$ \\
Tf BC & $2.00 \pm 0.27(8)$ & $2.86 \pm 0.14(7)$ & $3.00 \pm 0.33(3)$ & $2.50 \pm 0.17(18)$ \\
Tf BD & $1.50 \pm 0.26(2)$ & $2.50 \pm 0.49(2)$ & $2.00 \pm 0.49(2)$ & $2.17 \pm 0.35(6)$ \\
Tf CC & $1.92 \pm 0.16(14)$ & $1.67 \pm 0.14(12)$ & $2.00 \pm 0.20(5)$ & $1.94 \pm 0.13(31)$ \\
Tf CD & $1.75 \pm 0.18(12)$ & $1.80 \pm 0.16(10)$ & $2.00 \pm 0.17(9)$ & $1.84 \pm 0.14(31)$ \\
Tf DD & $1.33 \pm 0.33(3)$ & $1.50 \pm 0.49(2)$ & $2.00 \pm 0.50(2)$ & $1.57 \pm 0.28(7)$ \\
Tf DE & $1.84 \pm 0.09(52)$ & $2.11 \pm 0.17(45)$ & $2.31 \pm 0.10(32)$ & $2.05 \pm 0.23(129)$ \\
Overall & NS & $* *$ & NS & $*$ \\
$\quad$ Significant at & &
\end{tabular}

Figures in parenthesis indicate the number of animals. ${ }^{* *} \mathrm{P}<0.01{ }^{*} \mathrm{P}<0.05$.

of class I genetic markers, is the most heterogeneous polymorphic blood protein in sheep (Kuryl, 1992). Considerable polymorphism and various biological functions of transferrin resulted in a situation when it may be used as genetic markers of reproduction and production traits in sheep. The information on the association of transferrin polymorphism with the reproductive and productive traits of Garole sheep are scanty and probably no information is available regarding the lambing pattern with the relationship of transferrin polymorphism of Garole sheep. These associations will provide insight into the underlying mechanism of transferrin and results may be used in future breeding program. Hence, the objective of this research was to determine the association of phenovariants of transferrin on the different economic traits of Garole sheep.

\section{MATERIALS AND METHODS}

The present study was conducted on a flock of Garole sheep, maintained at Sheep and Goat Breeding Farm of West Bengal University of Animal and Fishery Sciences, during the period April to September, 2009. A total of 52 apparently healthy adult ewes were selected randomly from the stock of the farm. The transferrin polymorphisms were done by Vrtical SDS-Polyacrylamide Gel Electrophoresis technique, as described by Dogrul (1985) with few modifications. The identification of genotype was done by the method as described by Negi and Bhat (1980). Data on different economic traits like number of lambs produced (first, second and third lambing), age at first lambing (days) and lambing interval (days) of Garole sheep were collected from the records available in the sheep and goat breeding farm. Statistical analysis was done by using the SPSS program.
The effect of transferrin genotype on different economic traits (number of lambs in first, second and third lambing, age at first lambing, lambing interval) of ewes were analyzed by least square technique. The mean and standard error of the different economic traits under the study were calculated and all tests for significance were done by following standard methods described by Snedecor and Cochran (1967).

\section{RESULTS AND DISCUSSION}

\section{Association of transferrin types with prolificacy}

The analysis of data revealed that Garole sheep at this farm produced, overall $2.05 \pm 0.23$ lambs per lambing. Ewes with TfAD phenovarient showed best performance with respect to lamb production $(2.71 \pm 0.28$ lambs per lambing) and type TfDE phenovarient is least productive (1.57 \pm 0.28 lambs per lambing) in the analyzed flock. Garole sheep produced, on an average $1.84 \pm 0.09$, $2.11 \pm 0.17$ and $2.31 \pm 0.10$ lambs in first, second and third lambing, respectively (Table 1 ). In the first lambing the highest $(2.50 \pm 0.52$ lamb per lambing) and lowest (1.25 \pm 0.25 lambs per lambing) number of lambs were born by ewes with genotype TfBC and TfAA, respectively. In the second lambing the highest number of lambs $(3.00 \pm 0.49)$ was born by ewes with both genotype TfAD and TfBC, and the lowest number $(1.50 \pm 0.49)$ by ewes with genotype TfDE. Finding of Steppa et al. (2007) that in second lambing biggest number of lambs were born by ewes with genotype TfBC is in agreement with present study. In third lambing the highest number of lambs produced was observed for ewes with genotype both TfAD and TfBD which produced $3.00 \pm 0.40$ and $3.00 \pm 0.33$ 
lambs per lambing, while lowest number by ewes with TfBC genotype viz. $1.50 \pm 0.49$ lambs per lambing. From the result of this investigation it was observed that in first, second and third lambing highest number of lambs produced per lambing was observed ewes different transferrin genotypes. From the results it was observed that ewes with TfAD genotype showed best performance with respect to prolificacy $(2.71 \pm 0.28$ lambs per lambing) and type TfDE genotype is least productive $(1.57 \pm 0.28$ lambs per lambing) in the analyzed flock. Osman (1967) studied serum transferrin polymorphism in Desert sheep of Sudan and also suggested that some phenotypic combination may have some selective advantage for production traits in certain environment. Vanli and Bas (1994) observed that transferrin polymorphisms affected the number of lambs born in Awassis sheep. Rasmusen and Tucker (2009) reported that Finnish Landrace ewes of transferrin type TfBD had smaller litters than ewes of other types which is not in agreement with present study.

Analysis of variance showed that transferrin polymorphism had significant effect on number of lambs born in second ( $\left.{ }^{\star \star} P<0.01\right)$ and overall lambing ( $\left.* P<0.05\right)$. The research results of Vanli and Bas (1994) indicated that significant relationships between number of lambs or litter size and transferrin variants in Awassi sheep, is in agreement with results of present investigation. Analysis of variance also showed that transferrin polymorphism had non-significant effect on number of lambs born in first and third lambing. This result of present investigation is similar in trend to the findings of Weimer et al. (1984), who reported that no significant relationships between number of lambs or litter size and transferrin variants in Corriedale and Romney-Marsh sheep. Work of Darcan and Guney (2001) on a flock of Awassi and Cukurova Assaf sheep and no related to the effect of transferrin alleles on litter size is also in agreement with results of present investigation.

Analysis of number of lamb produced in first, second, third and overall lambing in respect of homozygous and heterozygous genotypes were also done. From the result of this analysis it was observed that on an average, the heterozygous ewes at the transferrin locus (TfAD, TfBC, TfBD, TfCD and TfDE) produce more number of lambs per lambing in first, second, third and overall lambing than the homozygous ewes (TfAA, TfBB, TfCC and TfDD) in respective lambing. Number of average lambs born per lambing in heterozygous and homozygous ewes were $1.97 \pm 0.27$ and $1.68 \pm 0.36$ (in first lambing), $2.20 \pm 0.19$ and $2.00 \pm 0.25$ (in second lambing), $2.50 \pm 0.51$ and $2.17 \pm 0.15$ (in third lambing) and $2.16 \pm 0.18$ and $1.99 \pm 0.25$ (in overall lambing) respectively (Table 3 ). Among the heterozygous ewes, the overall highest number of lambs born $(2.00 \pm 0.28)$ was met in ewes which had the TfA allele in combination with TfD allele. Also, better performance was seen in ewes in the TfB had combination with $\operatorname{TfD}(1.89 \pm 0.17)$ and $\operatorname{TfC}(1.83 \pm 0.35)$ alleles. Combination of The TfC and TfD allele showed lower performance and had produced $1.43 \pm 0.28$ lambs per lambing. Among the homozygous ewes at the transferrin locus overall the highest number of lambs born were observed for the TfCC ewes $(1.67 \pm 0.35)$. Ewes with TfBB genotype produced slightly lesser number of lambs per lambing $(1.64 \pm 0.25)$. The ewes having the TfAA and Tf DD genotype produced equal number $(1.58 \pm 0.14)$ of lambs per lambing. Results of Hrinca et al. (2008) showed that the heterozygous ewes at the Tf locus were more prolific than the homozygous ones at the same locus are in agreement with present study. They also observed that most prolific homozygous ewes were those with TfCC phenotype, correlates the finding of present study that overall the highest number of lambs born were observed for the TfCC ewes (2.17 \pm 0.35$)$. Analysis of variance showed that between genotype analysis had significant $\left({ }^{*} \mathrm{P}<0.05\right)$ effect on average number of lamb produced in overall lambing (Table 3 ).

It can come out that the transferrin heterozygous ewes have an obvious superior genotype comparatively with that of the Tf homozygous genotype. On an average, the heterozygous ewes at the Tf locus are more prolific than the homozygous ones at the same locus which may be due to heterotic effect or non additive genetic effect.

The research results of the present study also indicate that litter size increased progressively with advances in parity. These results agree with those obtained by Gabina (1989). It is well documented that litter size improves with advance in age through increased ovulation rate, uterine capacity and other maternal traits affecting the reproductive efficiency of the ewe (Fahmy, 1990).

\section{Association of transferrin types with age at first lambing}

It was found that the overall mean of age at first lambing was $479.88 \pm 4.27$ days. Maximum value of age at first lambing (522.25 \pm 22.56 days) corresponds to sheep having TfAA genotype. This value was followed by sheep having genotype TfCC (491.00 \pm 21.00 days), TfBB (485.25 \pm 16.98 days), TfDD (483.41 \pm 11.30 days), TfDE (483.33 \pm 20.08 days), $\operatorname{TfCD}(475.28 \pm 6.30$ days), TfBD (469.75 \pm 10.46 days) and $\operatorname{TfBC}(469.00 \pm 20.00$ days $)$ (Table 2). Lowest age at first lambing (447.00 \pm 13.00 days) was shown by animal having TfAD phenovarient. Ghatak (2001) reported that age at first lambing was higher for TfAA, TfBD, TfDD types transferrin in Muzaffarnagri sheep TfAC, TfAD, TfCD and TfDD transferrin types in Shahabadi sheep and TfBC, TfBD, TfCD and TfDD transferrin types in Garole sheep.

Analysis of variance showed that transferrin genotype had non-significant effect in case of age at first lambing, in the Garole sheep. Gopinathan and Nair (1976) did not find any significant relationship of transferrin with age at first kidding. Erokhin and Bashkeeva (1978) found no 
Table 2. Mean \pm SE of age at first lambing, lambing interval (in first, second and overall) in investigated flock of Garole sheep in respect of genotype.

\begin{tabular}{lcccc}
\hline \multirow{2}{*}{ Genotype } & \multicolumn{4}{c}{ Traits } \\
\cline { 2 - 5 } & AFL(days) & First lambing interval(days) & Second lambing interval (days) & Overall lambing interval(days) \\
\hline Tf AA & $522.25 \pm 22.56(4)$ & $254.75 \pm 9.19(4)$ & $273.75 \pm 9.95(4)$ & $276.50 \pm 20.56(2)$ \\
Tf AD & $447.00 \pm 13.00(3)$ & $246.00 \pm 10.03(2)$ & $238.33 \pm 14.16(3)$ & $264.25 \pm 6.89(8)$ \\
Tf BB & $485.25 \pm 16.98(4)$ & $237.50 \pm 8.53(4)$ & $251.50 \pm 4.51(2)$ & $237.86 \pm 7.37(7)$ \\
Tf BC & $469.00 \pm 20.00(2)$ & $271.50 \pm 15.55(2)$ & $261.66 \pm 14.26(3)$ & $261.50 \pm 9.75(4)$ \\
Tf BD & $469.75 \pm 10.46(8)$ & $260.00 \pm 7.81(7)$ & $276.00 \pm 17.34(2)$ & $260.50 \pm 6.16(10)$ \\
Tf CC & $491.00 \pm 21.00(2)$ & $255.50 \pm 12.53(2)$ & $260.00 \pm 11.61(5)$ & $265.75 \pm 9.75(4)$ \\
Tf CD & $475.28 \pm 6.30(14)$ & $258.41 \pm 4.26(12)$ & $244.50 \pm 8.52(2)$ & $258.88 \pm 4.73(17)$ \\
Tf DD & $483.41 \pm 11.30(12)$ & $248.10 \pm 7.25(10)$ & $259.00 \pm 3.57(32)$ & $251.42 \pm 4.47(19)$ \\
Tf DE & $483.33 \pm 20.08(3)$ & $270.50 \pm 25.57(2)$ & $\mathrm{NS}$ & $257.50 \pm 9.75(4)$ \\
Overall & $479.88 \pm 4.27(52)$ & $254.62 \pm 2.94(45)$ & $\mathrm{NS}$ & \\
Significant at & $\mathrm{NS}$ & $\mathrm{NS}$ & & \\
\hline
\end{tabular}

Figures in parenthesis indicate the number of animals. ${ }^{*} \mathrm{P}<0.01{ }^{*} \mathrm{P}<0.05$.

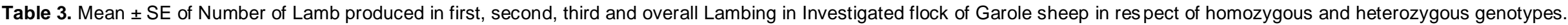

\begin{tabular}{|c|c|c|c|c|c|c|c|c|c|}
\hline \multirow{3}{*}{ Type } & \multirow{3}{*}{ Genotype } & \multicolumn{8}{|c|}{ Traits : Number of lamb produced in } \\
\hline & & \multicolumn{2}{|c|}{ First lambing } & \multicolumn{2}{|c|}{ Second lambing } & \multicolumn{2}{|c|}{ Third lambing } & \multicolumn{2}{|c|}{ Overall lambing } \\
\hline & & Lamb/ lambing & Overall & Lamb/ lambing & Overall & Lamb/ lambing & Overall & Lamb/ lambing & Overall \\
\hline \multirow{4}{*}{ Homozygous } & $\operatorname{Tf} A A$ & $1.25 \pm 0.25(4)$ & \multirow{4}{*}{$1.68 \pm 0.36$} & $2.50 \pm 0.25(4)$ & \multirow{4}{*}{$2.00 \pm 0.25(20)$} & $2.50 \pm 0.25(4)$ & \multirow{4}{*}{$2.17 \pm 0.15(18)$} & $2.08 \pm 0.25(12)$ & \multirow{4}{*}{$1.99 \pm 0.25(60)$} \\
\hline & Tf BB & $1.75 \pm 0.48(4)$ & & $1.75 \pm 0.25(4)$ & & $2.33 \pm 0.33(3)$ & & $1.91 \pm 0.25(11)$ & \\
\hline & $\mathrm{Tf} \mathrm{CC}$ & $1.50 \pm 0.26(2)$ & & $2.50 \pm 0.49(2)$ & & $2.00 \pm 0.49(2)$ & & $2.17 \pm 0.35(6)$ & \\
\hline & Tf DD & $1.75 \pm 0.18(12)$ & & $1.80 \pm 0.16(10)$ & & $2.00 \pm 0.17(9)$ & & $1.84 \pm 0.14(31)$ & \\
\hline \multirow{5}{*}{ Heterozygous } & $\operatorname{Tf} A D$ & $2.33 \pm 0.33(3)$ & \multirow{5}{*}{$1.97 \pm 0.27(30)$} & $3.00 \pm 0.49(2)$ & \multirow{5}{*}{$2.20 \pm 0.19(25)$} & $3.00 \pm 0.40(2)$ & & $2.71 \pm 0.28(7)$ & \multirow{5}{*}{$2.16 \pm 0.18(69)$} \\
\hline & Tf BC & $2.50 \pm 0.52(2)$ & & $3.00 \pm 0.49(2)$ & & $1.50 \pm 0.49(2)$ & & $2.33 \pm 035(6)$ & \\
\hline & Tf BD & $2.00 \pm 0.27(8)$ & & $2.86 \pm 0.14(7)$ & & $3.00 \pm 0.33(3)$ & $2.50 \pm 0.51(14)$ & $2.50 \pm 0.17(18)$ & \\
\hline & $\operatorname{Tf} C D$ & $1.92 \pm 0.16(14)$ & & $1.67 \pm 0.14(12)$ & & $2.00 \pm 0.20(5)$ & & $1.94 \pm 0.13(31)$ & \\
\hline & Tf DE & $1.33 \pm 0.33(3)$ & & $1.50 \pm 0.49(2)$ & & $2.00 \pm 0.50(2)$ & & $1.57 \pm 0.28(7)$ & \\
\hline \multirow{2}{*}{\multicolumn{2}{|c|}{$\begin{array}{l}\text { All population } \\
\text { Significant at }\end{array}$}} & \multicolumn{2}{|c|}{$1.84 \pm 0.09(52)$} & \multicolumn{2}{|c|}{$2.11 \pm 0.07(45)$} & \multicolumn{2}{|c|}{$2.31 \pm 0.10(32)$} & \multicolumn{2}{|c|}{$2.05 \pm 0.23$ (129) } \\
\hline & & \multicolumn{2}{|c|}{ NS } & \multicolumn{2}{|c|}{ NS } & \multicolumn{2}{|c|}{ NS } & \multicolumn{2}{|c|}{ * } \\
\hline
\end{tabular}

Figures in parenthesis indicate the number of animals. ${ }^{* *} \mathrm{P}<0.01{ }^{*} \mathrm{P}<0.05$.

clear relationship between transferrin alleles and reproduction traits of Kuibyshev sheep. Ghatak
(2001) observed no significant association of age at first lambing with transferrin phenotypes. Their findings are in agreement with the findings of present investigation. 
Analysis of age at first lambing in respect to homozygous and heterozygous genotypes was also done (Table 4). From the result of this analysis it was observed that on an average, the heterozygous ewes at the transferrin locus (TfAD, TfBC, TfBD, TfCD and TfDE) had shorter age at first lambing (471.323 \pm 5.26 days) with respect to homozygous ewes at transferrin locus (492.52 \pm 6.39 days). Among the heterozygous ewes at the Tf locus the highest age at first lambing was observed for TfDE ewes $(483.33 \pm 20.08$ days) and the lowest for the TfAD ewes (447.00 \pm 13.00 days). The other three heterozygous transferrin genotypes (TfBC, TfBD andTfCD) had $469.00 \pm 1.00,469.75 \pm 4.46$ and $475.28 \pm 6.30$ days of age at first lambing, respectively.Among the homozygous ewes at the Tf locus the highest age at first lambing was in the TfAA ewes(522.25 \pm 22.56 days) and the lowest is in the TfDD ones $(483.41 \pm 11.30$ days). The other two homozygous transferrin genotypes (TfBB and TfCC) had 485.25 \pm 6.98 and $491.00 \pm 21.00$ days of age at first lambing, respectively.

Between genotype analysis of variance showed that transferrin genotypes had significant $\left({ }^{\star \star} \mathrm{P}<0.01\right)$ effect on age at first lambing. Osman (1967) also suggested that some phenotypic combination may have some selective advantage for age at first lambing in certain environment in Desert sheep of Sudan

\section{Association of transferrin types with lambing interval}

Overall lambing interval was found to be $256.44 \pm 9.51$ days in the herd (Table 2). From the results of overall lambing interval it was observed that ewes having TfBB genotype had overall shortest lambing interval (237.86 \pm 7.37 days) while ewes having TfCC genotype had over all longest lambing interval (265.75 \pm 9.75 days). Further it was observed that mean first and second lambing interval was of $254.62 \pm 2.94$ and $259.00 \pm 3.57$ days, respectively. Maximum (271.50 \pm 15.55 days) and minimum (237.50 \pm 8.53 days) values of first lambing interval corresponds to the animals having TfBC and TfBB phenovarient, respectively. Maximum (276.50 \pm 20.56 days) and minimum (238.33 \pm 14.16 days) values of second lambing interval corresponds to the animal having TfAD and TfBB phenovarient, respectively. From the results of this investigation it was found that ewes of TfBB genotype had least first lambing interval, second lambing interval and overall lambing interval in the analyzed flock. Ghatak (2001) observed that Muzaffarnagri sheep having transferrin types TfDD, TfCD, TfBD had higher lambing interval than TfAA, TfAD and TfDE types. In case Shahabadi sheep lambing interval were higher for individuals having transferrin types TfAD, TfCC, TfCD and TfDD. In Garole sheep TfBD,Tf AD, TfDD, TfBD transferrin types had higher lambing interval than other.
Statistical analysis showed that there was nonsignificant effect of transferrin polymorphism on lambing interval of Garole sheep. This finding is in agreement with the finding of Ghatak (2001). Paul (2002) has also observed that there were no significant differences of kidding interval (months) due to transferrin types in Bengal goat, which can be correlated with the findings of present study in Garole sheep. Analysis of first lambing interval, second lambing interval and overall lambing interval with respect to homozygous and heterozygous genotypes was also done (Table 4). From the result of this analysis it was observed that on an average, the homozygous ewes at transferrin locus (TfAA, TfBB, TfCC and TfDD) had shorter age for respective traits with respect to heterozygous ewes at the transferrin locus (TfAD, TfBC, TfBD, TfCD and TfDE). The values for overall lambing interval, first lambing interval and second lambing interval were $253.13 \pm 3.20,248.05 \pm 4.25$ and $258.78 \pm 4.8$ days in homozygous ewes and $259.67 \pm 3.17$, $259.88 . \pm 3.7$ and $259.29 \pm 5.4$ days in heterozygous ewes respectively. Osman (1967) also suggested that some phenotypic combination of serum transferrin polymorphism may have some selective advantage for reproduction traits in certain environment for Desert sheep. Erokhin and Bashkeeva (1978) found no clear relationship between transferrin alleles and reproduction traits of Kuibyshev sheep.

Analysis of variance showed that transferrin genotypes had significant effect $(* P<0.05)$ in first lambing interval. Samasuddin et al.(1988) that significant association of kidding interval with TfAA(homozygous) in Saanen $\times$ Malabar crossbreds which may be due to the effect of exotic breed or crossbreeding can be compared with the result of present study. In conclusion, the heterozygous ewes tended to have a significantly better prolificacy than the homozygous ewes. This genetic information of transferrin gene could be useful in marker assisted selection to improve production performance. Selecting a flock of Garole sheep for improved prolificacy the transferrin genotype may be applied as an additional criterion and for the purpose of flock replacement.

\section{ACKNOWLEDGEMENT}

Authors are thankful to the Vice-Chancellor, West Bengal University of Animal and Fishery Sciences, 37 and 68 K.B. Sarani, Belgachia, Kol -37, West Bengal, India for providing the necessary facilities and co-operation during the course of this study.

\section{REFERENCES}

Darcan N, Guney O (2001). Effects of haemoglobin and transferrin polymorphism on the performance of Awassi and crossbred ewes under subtropic environment. J. Appl. Anim. Res., 19(2):187-192. 
Table 4. Mean \pm SE of age at first lambing and lambing interval (in first, second and overall) in investigated flock of Garole sheep in respect of homozygous and heterozygous genotypes.

\begin{tabular}{|c|c|c|c|c|c|c|c|c|c|}
\hline \multirow{3}{*}{ Type } & \multirow{3}{*}{ Genotype } & \multicolumn{8}{|c|}{ Traits } \\
\hline & & \multicolumn{2}{|c|}{ Age at first lambing } & \multicolumn{2}{|c|}{ First lambing interval } & \multicolumn{2}{|c|}{ Second lambing interval } & \multicolumn{2}{|c|}{ Overall lambing interval } \\
\hline & & Mean value & Overall & Mean value & Overall & Mean value & Overall & Mean value & Overall \\
\hline \multirow{4}{*}{ Homozygous } & Tf $A A$ & $522.25 \pm 22.56(4)$ & \multirow{4}{*}{$492.52 \pm 6.39(22)$} & $254.75 \pm 9.19(4)$ & \multirow{4}{*}{$248.05 \pm 4.25(20)$} & $273.75 \pm 9.95(4)$ & \multirow{4}{*}{$258.78 \pm 4.84(18)$} & $264.25 \pm 6.89(8)$ & \multirow{4}{*}{$253.13 \pm 3.20(38)$} \\
\hline & Tf BB & $485.25 \pm 6.98(4)$ & & $237.50 \pm 8.53(4)$ & & $238.33 \pm 14.16(3)$ & & $237.86 \pm 7.37(7)$ & \\
\hline & Tf CC & $491.00 \pm 21.00(2)$ & & $255.50 \pm 12.53(2)$ & & $276.00 \pm 17.34(2)$ & & $265.75 \pm 9.75(4)$ & \\
\hline & Tf DD & $483.41 \pm 11.30(12)$ & & $248.10 \pm 7.25(10)$ & & $255.11 \pm 2.96(9)$ & & $251.42 \pm 4.47(19)$ & \\
\hline \multirow{5}{*}{ Heterozygous } & Tf $A D$ & $447.00 \pm 13.00(3)$ & \multirow{5}{*}{$471.323 \pm 5.26(30)$} & $246.00 \pm 10.03(2)$ & \multirow{5}{*}{$259.88 \pm 3.79(25)$} & $276.50 \pm 20.56(2)$ & & $261.25 \pm 9.75(4)$ & \multirow{5}{*}{$259.67 \pm 3.17(39)$} \\
\hline & Tf BC & $469.00 \pm 1.00(2)$ & & $271.50 \pm 15.55(2)$ & & $251.50 \pm 4.51(2)$ & & $261.50 \pm 9.75(4)$ & \\
\hline & Tf BD & $469.75 \pm 4.46(8)$ & & $260.00 \pm 7.81(7)$ & & $261.66 \pm 14.26(3)$ & $259.29 \pm 5.48(14)$ & $260.50 \pm 6.16(10)$ & \\
\hline & Tf CD & $475.28 \pm 6.30(14)$ & & $258.41 \pm 4.26(12)$ & & $260.00 \pm 11.66(5)$ & & $258.88 \pm 4.73(17)$ & \\
\hline & Tf DE & $483.33 \pm 20.08(3)$ & & $270.50 \pm 25.57(2)$ & & $244.50 \pm 8.52(2)$ & & $257.50 \pm 9.75(4)$ & \\
\hline \multicolumn{2}{|l|}{ All population } & \multicolumn{2}{|c|}{$479.88 \pm 4.27(52)$} & \multicolumn{2}{|c|}{$254.62 \pm 2.94(45)$} & \multicolumn{2}{|c|}{$259.00 \pm 3.57(32)$} & \multicolumn{2}{|c|}{$256.44 \pm 9.51(77)$} \\
\hline Significant at & & \multicolumn{2}{|c|}{$* *$} & \multicolumn{2}{|c|}{ * } & \multicolumn{2}{|c|}{ NS } & \multicolumn{2}{|c|}{ NS } \\
\hline
\end{tabular}

Figures in parenthesis indicate the number of animals. ${ }^{* *} \mathrm{P}<0.01{ }^{*} \mathrm{P}<0.05$.

Dogrul F (1985). Transferrin and haemoglobin types in different sheep breeds. J. Etlik Vet. Anim. Sci., 5: 61-73 [c.f Anim. Breeds, Abst. 55(4): 2172].

Erokhin Al, Bashkeeva MF (1978). Fattening and carcass characteristics of Kuibysher sheep of different transferrin type. Vsess. Nanch. Issle.Ins.Zhivo, 46: 121-124.

Fahmy MH (1990). Development of DLS breed of sheep: Genetic and Phenotypic parameters of date of lambing and litter size. Can. J. Anim. Sci., 70: 771-778.

Gabina D (1989). Improvement of the reproductive performance of Rasa Aragonesa flocks in frequent lambing systems. Effects of management system, age of ewe and season. Livest. Prod. Sci., 22: 69-85.

Ghatak S (2001). Haemoglobin and Transferrin polymorphism in four breeds of sheep and their association with certain economic traits. M.V.Sc. thesis submitted to W.B.U.A.F.Sc., West Bengal.

Gopinathan N, Nair PG (1976). Genetic studies on haemoglobin and transferrin polymorphism in goats and their relationship with production traits. In Proceedings of Second Workshop of A.I.C.R.P. on Goat Breeding held at the N.D.R.I.,Karnal. p. 24 [c.f. Indian J. Anim. Sci., 1980, 50(7): 576-579].
Hrinca GH, Groza M, Elena F, Padeanu I, Voia S, Ursu S Chiorescu I (2008). Association of some biochemicalgenetic markers with the production parameters of the Botosani Karakul ewes. Lucrari stiintifice Zootehnie si Biotehnologii, 41(2): 751-757.

Kuryl J (1992). Markery genetyczne. Zesz. Nauk. Przegl. Hod, 6: 48-76.

Negi PR, Bhat PP (1980). Note on the genetic variability of blood serum proteins and enzymes in Gaddi sheep and halfbreds with Rambouillet and Russian Merino. Indian J. Anim. Sci., 50: 1004-1008.

Osman HEIS (1967). Serum Transferrin polymorphism in the Desert sheep of the Sudan. Nature, 215: 162-163.

Paul R (2002). Transferrin polymorphism and its relationship with some physical and reproductive traits in different colour varieties of Bengal Goat. M.V..Sc. Thesis submitted to W.B.U.A.F.Sc., West Bengal.

Rasmusen BA, Tucker EM (2009). Transferrin types and reproduction in sheep. Anim. Genet., 4(4): 207-220.

Shamsuddin AK, Nanda Kumaran R, Mukundan G (1988). Electrophoretic studies on transferrin polymorphism in Malabari goats and its exotic crossbreds. Indian J. Anim Sci., 58(10): 1231-1233.
Snedecor GW, Cochran WG (1967). Statistical methods. Sixth Edition. The lowa State University Press. American lowa, U.S.A.

Steppa R, Slosarz P, Strojna A, Stanisz M (2007). Transferrin genotypes as genetic markers of lifetime prolificacy of ewes in a flock of prolific sheep 09. Annales Universitatis Mariae Curie-Sklodowska Lublin- Polonia. XXV(I): 55-62.

Vanli Y, Bas S (1994). Genetics of beta -globulin (transferrin) polymorphism and its association with quantitative traits in Ataturk University flocks. Turk. J. Vet. Anim. Sci., 18(6): 391-396.

Weimer TA, Franko MHP, Moraes JCF (1984). Hemoglobin and Transferrin types in Corriedale and Romney Marsh sheep in Brazil. Rev. Bras. Genet. 7: 287-297. 